\title{
Benefit of hydrocortisone, thiamine, and vitamin C for patients with sepsis or septic shock? Too early to draw conclusions
}

\author{
Rui Shi ${ }^{1,2}$ and Hongtao Tie $^{3 *}$ (D)
}

Keywords: Hydrocortisone, Thiamine, And vitamin C, Sepsis or septic shock, Meta-analysis

\section{Dear Editor,}

Previous studies demonstrated that a combination of hydrocortisone, vitamin $\mathrm{C}$, and thiamine (HVT) is a promising adjuvant treatment for sepsis and septic shock, with decreased mortality and improved resolution of disease [1]. However, recently published prospective, randomized controlled trials (RCTs) did not support this finding [2]. Therefore, we performed a meta-analysis to evaluate the efficacy of HVT treatment for patients with sepsis or septic shock.

This meta-analysis was performed strictly following the Preferred Reporting Items for Systematic Reviews and Meta-analysis (PRISMA) statement [3]. The primary outcomes were mortality, decrease of sequential organ failure assessment score from baseline (Delt SOFA), and time of vasopressors use. Relative risk (RR) with 95\% confidence intervals (CIs) and weighted mean differences (WMDs) with 95\% CIs were used. Meta-analyses were performed using a random-effects model by RevMan version 5.1.

Four RCTs with 528 patients and five cohorts involving 412 patients were included, as described in Table 1 . As shown in Fig. 1, pooled results from RCTs showed that HVT has no benefit on mortality (RR $0.92,95 \% \mathrm{CI}$ 0.69 to $1.24, p=0.59 ; I^{2}=0 \%, P_{H}=0.69$ ), while it was associated with a significant decrease of SOFA (Delt SOFA: WMD $-1.02,95 \% \mathrm{CI}-1.31$ to $-0.73, p<0.001 ; I^{2}=0 \%$,

\footnotetext{
* Correspondence: hongtaotie@163.com

${ }^{3}$ Department of Cardiothoracic Surgery, The First Affiliated Hospital of Chongqing Medical University, Chongqing 400016, China

Full list of author information is available at the end of the article
}

$\left.P_{H}=0.80\right)$ and reduction in time of vasopressors use (WMD $-21.77 \mathrm{~h}, 95 \% \mathrm{CI}-29.26$ to $-14.29, p<0.001 ; I^{2}=$ $\left.0 \%, P_{H}=0.4\right)$. Overall results from cohorts revealed that HVT could significantly reduce mortality (RR0.46, 95\%CI 0.25 to $\left.0.86, p=0.01 ; I^{2}=75 \%, P_{H}=0.001\right)$ and SOFA score (Delt SOFA: WMD $-2.21,95 \% \mathrm{CI}-4.22$ to $-0.20, p=0.03$; $\left.I^{2}=81 \%, P_{H}=0.005\right)$, but not the duration of vasopressors use (WMD $1.11 \mathrm{~h}, 95 \% \mathrm{CI}-59.60$ to $61.82, p=0.97 ; I^{2}=$ $\left.98 \%, P_{H}<0.001\right)$. No differences in intensive care unit (ICU) length of stay and hospital length of stay between the HVT and the control group were observed.

Our study suggested that HVT has potential beneficial effects. A significant reduction in SOFA score was observed, although no benefit of mortality in the pooled effect of RCTs. Since it is a valuable end-point reflecting the disease process and also a surrogate marker for mortality, our meta-analysis of the four small RCTs might be inadequate to detect a mortality benefit. Additionally, the improved resolution of shock from RCTs also supports HVT use.

A generally recognized concept is that the HVT could synergistically restore the dysregulated immune system, oxidative mitochondrial function, and energy production [4]. However, current clinical practice regarding the HVT strategy is still debating. Besides the potential synergistic beneficial effects, the arguments supporting the use of HVT include low risk, low cost, and easy availability. Minor clinical side effects, such as hyperglycemia, hypertension, and hypernatremia induced by hydrocortisone [5], might occur but are insignificant and easily managed in ICU. 


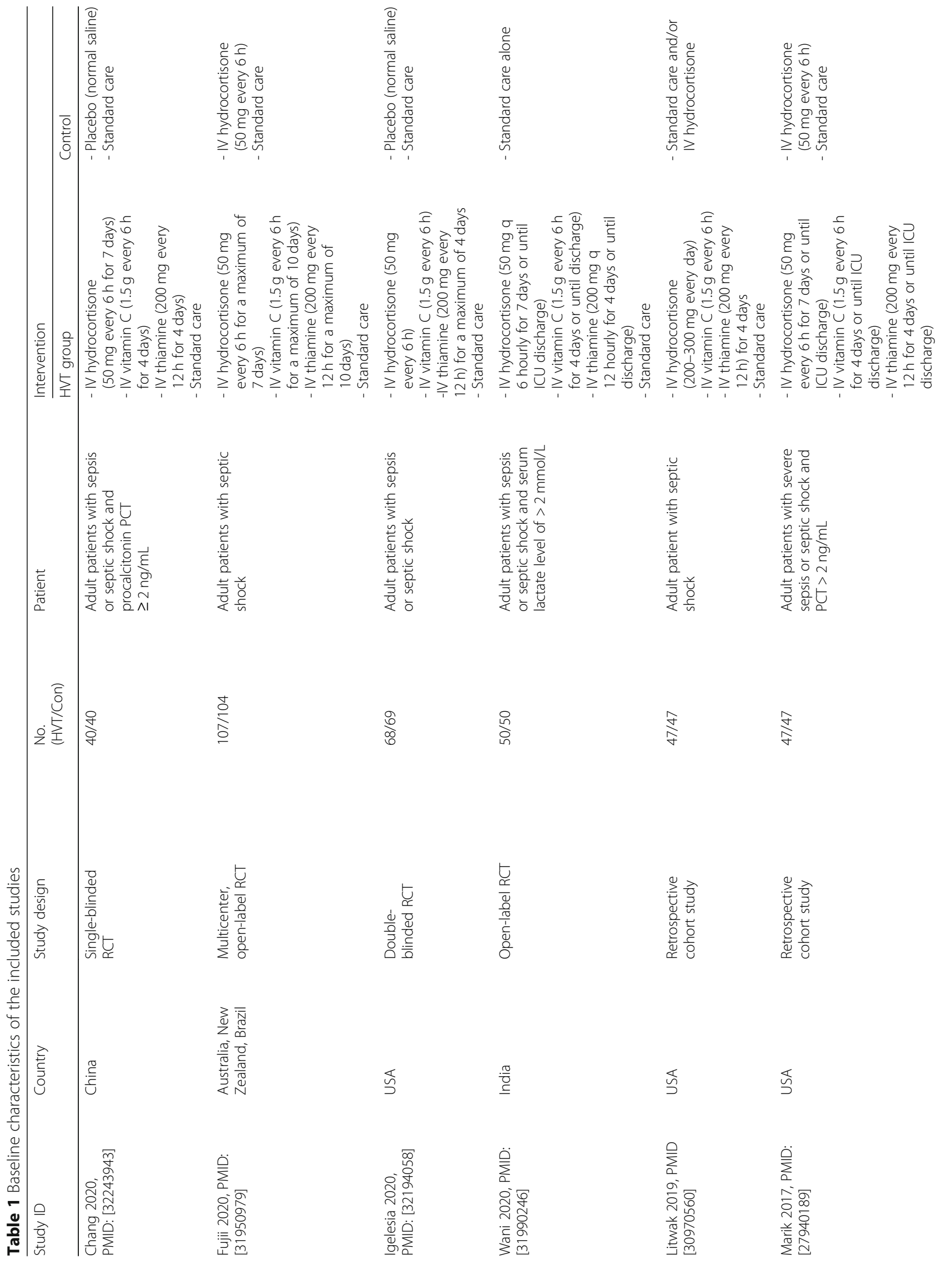


Chi and Tie Critical Care $\quad$ (2020) 24:431

Page 3 of 5

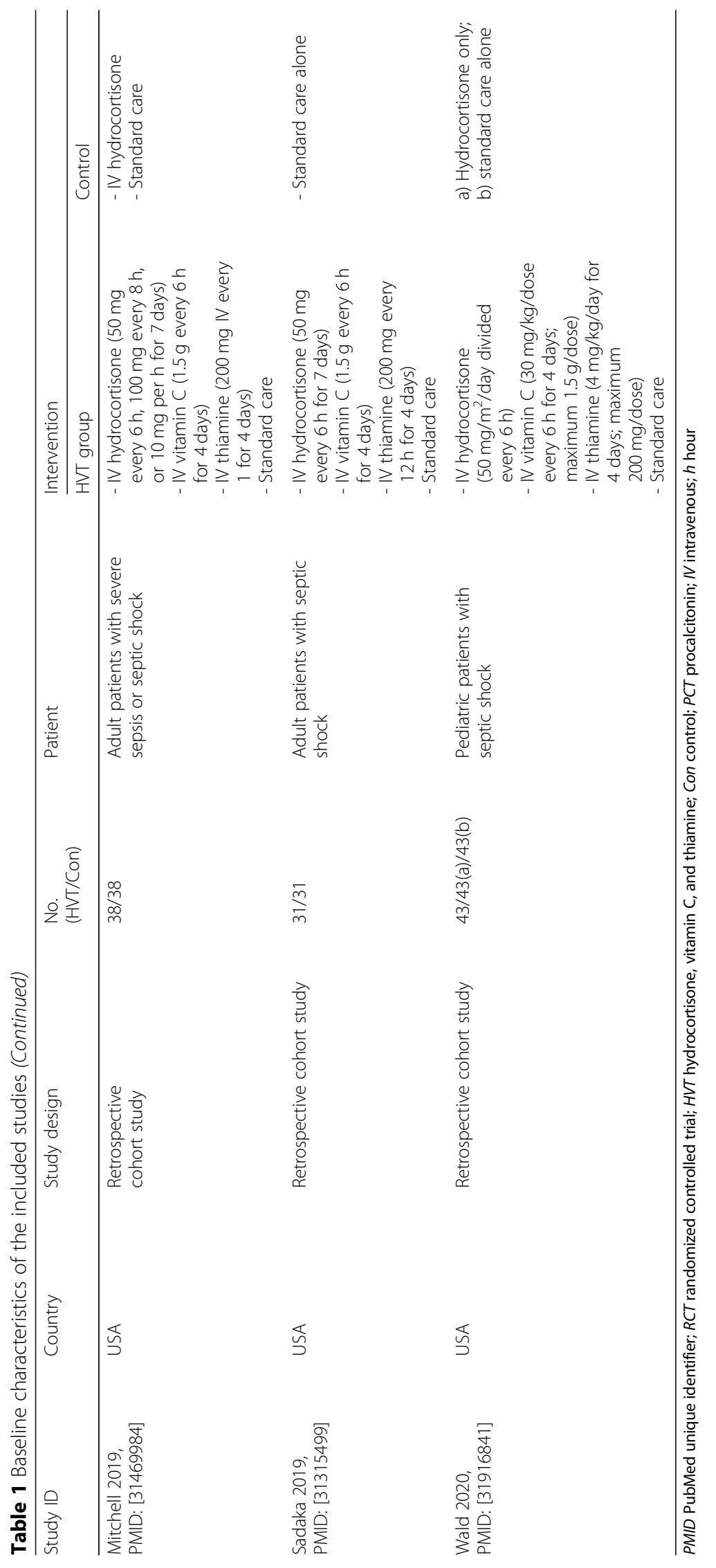



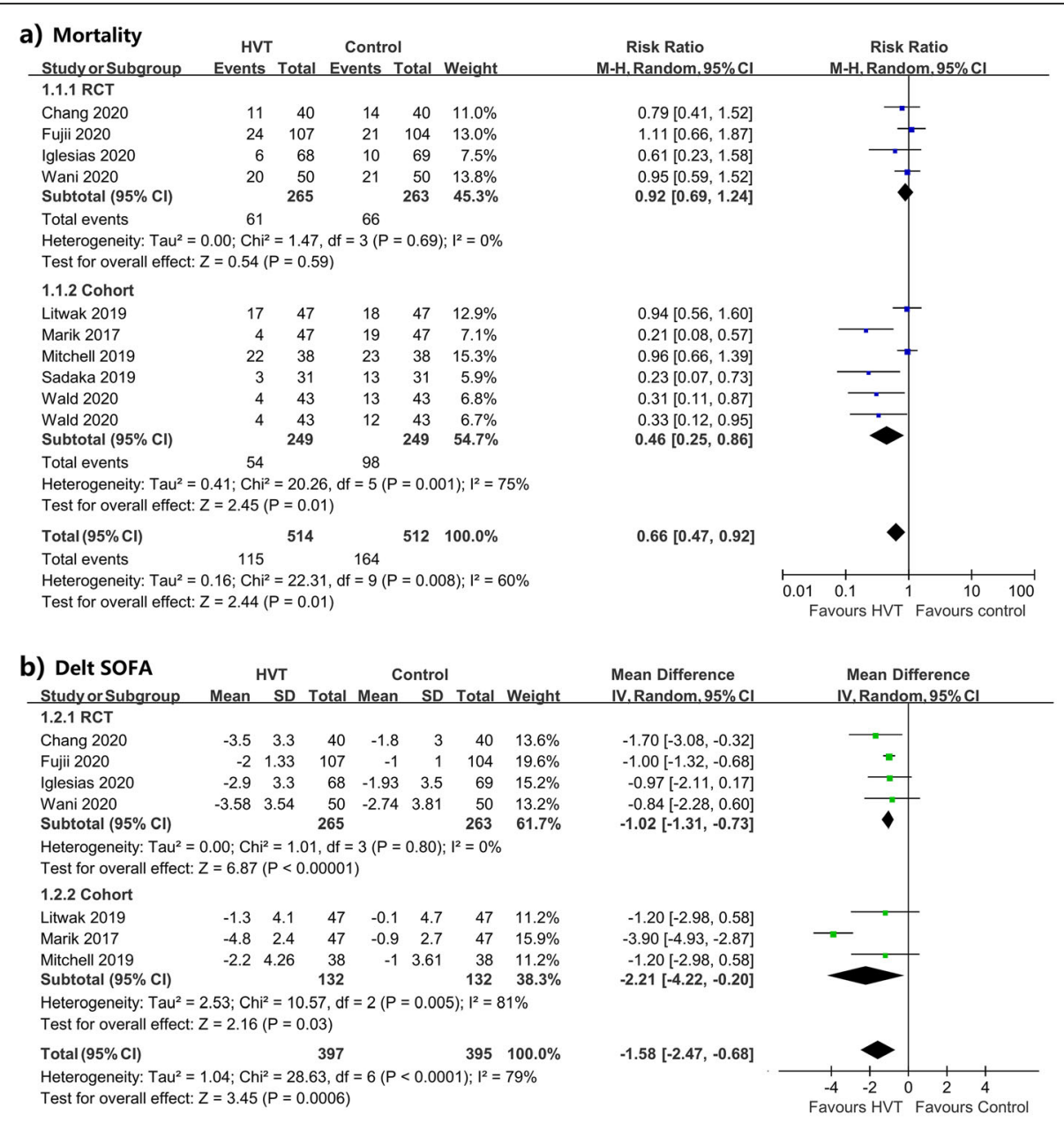

c) Time of vasopressors use

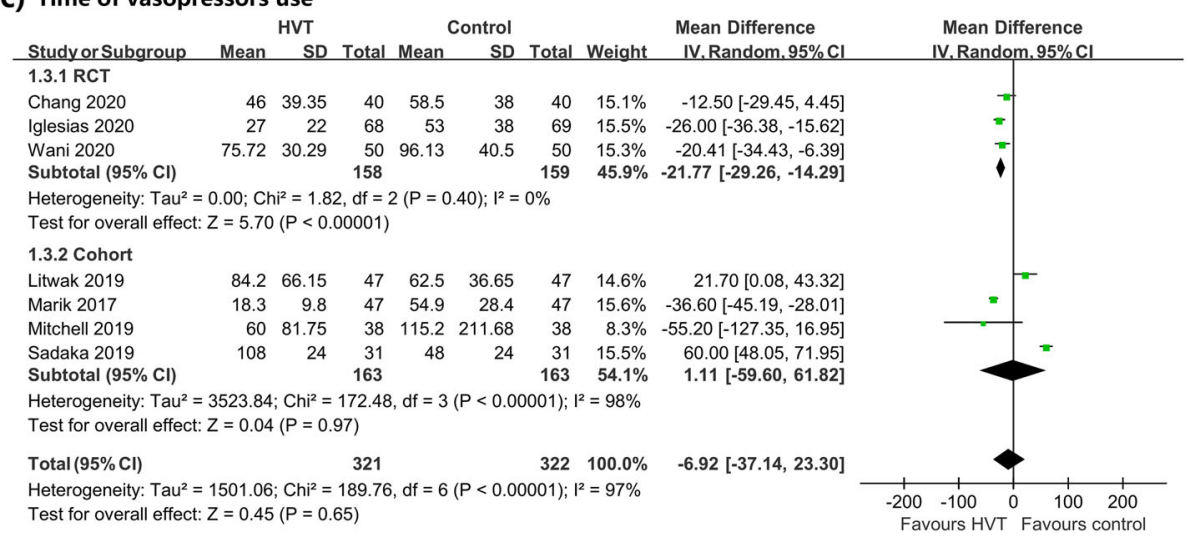

Fig. 1 Forest plots for the primary outcome. a Mortality. b Delt SOFA. c Time of vasopressors use

Some limitations merit consideration. Sample sizes in RCTs are small, and pooled effects on different outcomes are inconsistent. Though potential bias in cohort studies, the pooled result of cohort studies in our study supported and consolidated the findings from RCTs. Additionally, hydrocortisone was not systematically used for control groups in RCTs and cohorts. It is thus questionable to determine the benefit is from the synergistic effect of HVT or corticosteroid only, since the beneficial effect of corticosteroid sole has been well established [6]. Besides, other clinical heterogeneities, such as the timing of HVT and severity of the disease, should also be 
regarded. However, the data sparseness of included studies limited our subgroup analysis for further exploration.

In conclusion, the beneficial findings of our study support that HVT remains an attractive choice for sepsis and septic shock, while results from large-scale RCTs are still expected before a definite conclusion, especially in terms of the timing of HVT and the severity of sepsis.

\section{Abbreviations}

HVT: Hydrocortisone, vitamin C, and thiamine; RCTs: Randomized controlled trials; WMDs: Weighted mean differences; RR: Relative risks; Cls: Confidence intervals

\section{Acknowledgements}

None.

\section{Authors' contributions}

RS and HTT conceived the study, participated in the design, and collected the data. HTT performed the statistical analyses. RS drafted the manuscript. HTT revised the manuscript critically for important intellectual content. All authors read and approved the final manuscript.

\section{Authors' information}

$\mathrm{HTT}$ is now working as a cardiothoracic surgeon in the Department of Cardiothoracic Surgery, The First Affiliated Hospital of Chongqing Medical University.

\section{Funding}

None.

\section{Availability of data and materials}

The datasets used and analyzed during the current study are available from the corresponding author on reasonable request.

Ethics approval and consent to participate

Not applicable

\section{Consent for publication}

Not applicable

\section{Competing interests}

The authors declare that they have no competing interests.

\section{Author details}

'Service de Médecine Intensive - Réanimation, Hôpital Bicêtre, AP-HP, Université Paris-Saclay, Le Kremlin-Bicêtre, France. ${ }^{2}$ INSERM UMR_S999 LabEx - LERMIT, Hôpital Marie-Lannelongue, Le Plessis Robinson, France. ${ }^{3}$ Department of Cardiothoracic Surgery, The First Affiliated Hospital of Chongqing Medical University, Chongqing 400016, China.

Received: 28 May 2020 Accepted: 5 July 2020

Published online: 14 July 2020

\section{References}

1. Marik PE, Khangoora V, Rivera R, Hooper MH, Catravas J. Hydrocortisone, vitamin $C$, and thiamine for the treatment of severe sepsis and septic shock: a retrospective before-after study. Chest. 2017;151(6):1229-38.

2. Fujii T, Luethi N, Young PJ, et al. Effect of vitamin C, hydrocortisone, and thiamine vs hydrocortisone alone on time alive and free of vasopressor support among patients with septic shock: the VITAMINS Randomized Clinical Trial. JAMA, 2020:323(5):423-31.

3. Moher D, Liberati A, Tetzlaff J, et al. Preferred Reporting Items for Systematic Reviews and Meta-Analyses: the PRISMA statement. Ann Intern Med. 2009; 151(4):264-9.

4. Marik PE. Hydrocortisone, ascorbic acid and thiamine (HAT therapy) for the treatment of sepsis. Focus on Ascorbic Acid Nutrients. 2018;10(11):1762.

5. Briegel J, Huge V, Möhnle P. Hydrocortisone in septic shock: all the questions answered? J Thorac Dis. 2018;10(Suppl 17):S1962-5.
6. Rygard SL, Butler E, Granholm A, et al. Low-dose corticosteroids for adult patients with septic shock: a systematic review with meta-analysis and trial sequential analysis. Intensive Care Med. 2018;44(7):1003-16.

\section{Publisher's Note}

Springer Nature remains neutral with regard to jurisdictional claims in published maps and institutional affiliations.

\section{Ready to submit your research? Choose BMC and benefit from:}

- fast, convenient online submission

- thorough peer review by experienced researchers in your field

- rapid publication on acceptance

- support for research data, including large and complex data types

- gold Open Access which fosters wider collaboration and increased citations

- maximum visibility for your research: over $100 \mathrm{M}$ website views per year

At BMC, research is always in progress.

Learn more biomedcentral.com/submissions 